\title{
Gender, age, social disadvantage and quitting smoking in Argentina and Uruguay
}

\author{
Mirosław Niedzin', Ewelina Gaszyńska², Jan Krakowiak³, Tomasz Saran, Franciszek Szatko², \\ Dorota Kaleta'
}

\author{
${ }^{1}$ Department of Tobacco Control, Preventive Medicine, Medical University of Lodz, Poland \\ 2 Department of Hygiene and Epidemiology, Medical University of Lodz, Poland \\ ${ }^{3}$ Department of Social Medicine, Medical University of Lodz, Poland \\ ${ }^{4}$ Department of Rehabilitation, Witold Chodźko Institute of Rural Health in Lublin, Poland
}

Niedzin M, Gaszyńska E, Krakowiak J, Saran T, Szatko F, Kaleta D. Gender, age, social disadvantage and quitting smoking in Argentina and Uruguay. Ann Agric Environ Med. 2018; 25(1): 100-107. doi: 10.5604/12321966.1227646

\begin{abstract}
Introduction. Cessation of tobacco use has the potential to provide the greatest immediate benefits for tobacco control. Understanding the social determinants of smoking cessation is an essential requirement for increasing smoking cessation at the population level. The purpose of this study was to analyze the socio-economic dimensions associated with cessation success among adults in Argentina and Uruguay.

Materials and methods. Data from the Global Adult Tobacco Survey (GATS), a cross-sectional, population-based, nationally representative survey conducted in Argentina $(n=5,383)$ and Uruguay $(n=4,833)$ was utilized. Univariable and multivariable logistic regression analyses with results being presented as odds ratios (OR) with $95 \%$ confidence intervals were applied to study differences among those respondents who sustained smoking abstinence ( $\geq 1$ year) and those who continued smoking.

Results. The GATS study revealed that social gradients in tobacco quitting exist in Argentina and Uruguay. Being aged 25-34, particularly men in Uruguay, women in Argentina, low educated men in Argentina and having a lower asset index were associated with reduced odds for quitting.

Conclusion. Factors that are driving differences in smoking cessation between diverse social groups in Latin America countries need to be considered when implementing relevant interventions to ensure tobacco control strategies work effectively for all population segments.
\end{abstract}

\section{Key words}

tobacco smoking cessation, socio-economic factors, adults, GATS, Argentina, Uruguay

\section{INTRODUCTION}

The 145 million smokers in the Region of the Americas account for $12 \%$ of the more than 1 billion smokers in the world [1]. The region lies in the fourth place among the six regions of the World Health Organization (WHO) with a 22\% smoking rate among the adult population [1]. Tobacco is a major preventable risk factor for major non-communicable chronic diseases (NCDs), which are currently responsible for almost two-thirds of deaths worldwide. In the Region of the Americas, NCDs are responsible for $77 \%$ of all deaths: among these, tobacco is responsible for $15 \%$ of deaths from cardiovascular diseases, $26 \%$ of deaths from cancer, and $51 \%$ of deaths from respiratory diseases [1]. According to the WHO, tobacco use and exposure to secondhand smoke kill about 1 million people annually in the Americas [2]. In Argentina, tobacco is responsible for $14 \%$ of all NCDs, compared with $8 \%$ of all communicable diseases [2].

Despite some decrease observed during recent years, high smoking prevalence and related harm still remains a significant public health concern in Argentina and Uruguay $[1,3]$. Apart from preventing smoking tobacco among young people, encouraging cessation is essential to ending the

Address for correspondence: Dorota Kaleta, Department of Tobacco Control, Preventive Medicine, Medical University of Lodz, Poland

E-mail: dkaleta@op.pl

Received: 19 July 2015; accepted: 14 September 2015; first published on December, 2016 tobacco epidemic. Cessation of tobacco use has the potential to provide the most immediate benefits of tobacco control and maximize the benefits in terms of preventable disease morbidity and mortality [4]. However, achieving substantial improvement will depend on successful implementation of the relevant tobacco control measures that can increase the smoking cessation rate at the population level in Argentina, Uruguay and other Latin America countries. In general, smoking prevalence and tobacco consumption is much higher in certain social groups [5]. Correspondingly, an increased susceptibility to tobacco related illnesses was found in low income groups, especially in all-cause mortality, lung diseases and low birth weight [5]. Likewise, several studies have indicated the social gradient in tobacco use in Argentina as well as in Uruguay. Fleischer et al. showed that better socio-economic status, measured through education, was related to less smoking and higher odds for recent quitting [6]. The most recent study by De Maio et al. revealed social gradients in tobacco use, exposure to secondhand smoke and cessation attempts among Argentinians and Uruguayans [3]. Therefore, social context cannot be overlooked when discussing applicable strategies to improve the design and implementation of appropriate tobacco policies and cessation programs in both countries. Data on the factors associated with successful smoking cessation that can be analyzed by socioeconomic factors beyond age and gender are crucial for the development of potential, high-impact population smoking cessation strategy [7]. In view of that, the purpose 
of our study was to examine the socio-economic dimensions associated with successful smoking cessation among adults in Argentina and Uruguay.

\section{MATERIALS AND METHOD}

The data source was the Global Adult Tobacco Survey (GATS) Argentina 2012 and Uruguay 2009. The GATS was implemented in Argentina by the Bureau of Health Promotion and Control of Non-communicable Diseases, the Ministry of Health of the Nation and the Coordination of Special Surveys of the Bureau of Household Income and Expenditures Studies of the National Institute of Statistics and Censuses [8]. In Uruguay, GATS was coordinated by the National Program for Tobacco Control of the Ministry of Public Health (MSP), implemented by the National Institute of Statistics (INE) with the assistance of the Latin American Center for Human Economics (CLAEH) [9]. GATS is a nationally representative household survey designed to monitor key tobacco control indicators. The target population of GATS includes all non-institutionalized men and women 15 years of age or older. The study protocol and questionnaire is based on standard methodology with some country-specific adaptations. Detailed methodology of the survey has been described elsewhere $[8,9,10]$. A multi-stage, geographically-clustered sample design was used to produce nationally representative data. The GATS questionnaires were administrated by trained survey staff during in-person interviews. There was a total of 6,645 and 5,581 completed individual interviews with an overall response rate of $74.3 \%$ in Argentina and $95.6 \%$ in Uruguay. The missing data were excluded from the analysis. After exclusion of respondents younger than 25 years, the final sample used in this study consisted of 5,383 Argentineans and 4,833 Uruguayans.

Study variables. The main outcome variable was successful smoking cessation among adults in Argentina. Previous studies on quitting smoking are not homogenous in defining successful quitting, and many different measures of success have been suggested $[11,12,13,14]$. Some studies have shown that the risk of relapse is relatively high for people who abstain from smoking for short periods, and are at the early stages of smoking cessation. About $65 \%-75 \%$ of these groups at risk would relapse within a year $[11,12,15,16]$. In the presented study, successful quitting is defined as having abstained from smoking for a year or more [17]. A sustained quitter was defined as a former daily smoker who had been smoking for at least 1 year or longer, and had stopped smoking for 12 months or more prior to the interview. Those subjects who had given up smoking in more recent periods were considered recent quitters. A continuous smoker was defined as a current daily smoker who had smoked more than an average of one cigarette per day on a regular basis for at least one year. The ever smokers group compriseds all the above-mentioned categories, including respondents who were current, former smokers and recent quitters. Overall lifetime cessation rates or 'quit rates' were calculated, as the number of former smokers divided by the number of ever smokers and multiplied by $100 \%$ [18].

The independent variables applied for determining associations of successful cessation were demographics: gender (male, female) and age of the respondents. Age was studied in five groups: $25-29,30-39,40-49,50-59$, and $\geq 60$ years old. Age at smoking onset - the age at which respondents started to smoke tobacco on a regular basis was also considered ( $\leq 17,18-20,21$ years or over). Moreover, socio-economic status, including education, economic activity, monthly household income and ownership of different household items were evaluated. Educational attainment was regarded as: primary or less, secondary, and higher education. Economic activity differentiated subjects who were currently employed, self-employed, homemakers, unemployed.

The variable called 'asset index' was created, based on a summative score of possession of the following assets: functioning electricity, flush toilet, fixed telephone, cell telephone, television, radio, refrigerator, car, washing machine, computer, internet access. The summative score was then divided into, high, medium low. Analogous methodology has been implemented elsewhere [19]. Additionally, awareness of the negative health consequences of smoking was assessed. Respondents were categorized as aware (those who answered 'yes' to the question: 'Do you think that tobacco smoking causes serious diseases?'), and not aware (those who answered 'no' and 'do not know'). Similarly, awareness of the adverse health consequences of environmental tobacco smoke (ETS) exposure was determined, and respondents were characterized as aware and not aware. Cohabitation with a smoker (yes, no) was also taken into account.

Analysis and statistics. The STATISTICA Windows XP version 8.0 programme was used to carry out the statistical analysis. All analyses were performed separately for men and women. Firstly, a descriptive analysis for all variables involved in the analysis was completed. Categorical variables were studied by chi-square test. Univariable and multivariable logistic regression analyses, with results being presented as odds ratios (OR) with 95\% confidence intervals, was applied to study differences among those respondents who sustained smoking abstinence for one year or longer with those who continued smoking. In multivariable analyses, all statistically significant socio-economic variables were simultaneously included in the model. Significance level for relevant calculations was set at 0.05 .

\section{RESULTS}

The characteristics of the respondents are described in Table 1. In Argentina and Uruguay, there are more ever male smokers than female smokers. Argentina recorded 40.7\% male smokers vs. $25.8 \%$ female smokers, and Uruguay had $60.4 \%$ male vs. $36.1 \%$ female smokers ( $\mathrm{p} \leq 0.001$ ). Similarly in both countries, more men started smoking before women, before or by the age of 17 , while more women started smoking before men by or after the age of 21 . Before or by the age of 17 , $58.0 \%$ men and $43.0 \%$ women started smoking in Argentina, and $58.6 \%$ men and $47.5 \%$ women in Uruguay ( $\mathrm{p} \leq 0.001)$. On the other hand, $23.4 \%$ women vs. $11.6 \%$ men in Argentina and $24.9 \%$ women vs. $9.8 \%$ men in Uruguay started smoking later by or after the age of 21 ( $\mathrm{p} \leq 0.001)$. Smokers in both countries differed by economic activity. Male smokers and quitters in Uruguay tended to be older than their counterparts in Argentina, while the women were quite similar in age. The average age of male ever smokers in Argentina was 47.8 \pm 15.3 
Table 1. Characteristics of the study population - Global Adult Tobacco Survey Argentina 2012 and Global Adult Tobacco Survey Uraguay 2009

\begin{tabular}{|c|c|c|c|c|c|c|}
\hline & \multicolumn{3}{|c|}{ Argentina } & \multicolumn{3}{|c|}{ Uruguay } \\
\hline & Men (n\%) & Women (n\%) & Total (n\%) & Men $(n \%)$ & Women $(\mathrm{n} \%)$ & Total (n\%) \\
\hline Quit rate & $38.9 \%$ & $39.6 \%$ & $39.2 \%$ & $52.7 \%$ & $50.1 \%$ & $51.7 \%$ \\
\hline Long-term quitters & $377(92.6 \%)$ & $307(89.0 \%)$ & $684(91.0 \%)$ & 720 (94.2\%) & $465(91.9 \%)$ & $1185(93.3 \%)$ \\
\hline Recent quitters & $30(7.4 \%)$ & $38(11.0 \%)$ & $68(9.0 \%)$ & $44(5.8 \%)$ & $41(8.1 \%)$ & $85(6.7 \%)$ \\
\hline Current smokers (total) & $563(23.6 \%)$ & $430(14.3 \%)$ & $992(18.4 \%)$ & $600(26.6 \%)$ & $423(16.4 \%)$ & $1023(21.2 \%)$ \\
\hline Current smokers who attempted to quit in the past year & $231(41.1 \%)$ & $182(42.3 \%)$ & $413(41.6 \%)$ & $243(40.5 \%)$ & $186(44.0 \%)$ & 429 (41.9\%) \\
\hline Current smokers who did not attempt to quit in the past year & $331(58.9 \%)$ & $248(57.7 \%)$ & $579(58.4 \%)$ & $357(59.5 \%)$ & $237(56.0 \%)$ & $594(58.1 \%)$ \\
\hline Ever smokers & $969(40.7 \%)^{* * *}$ & $775(25.8 \%)$ & $1744(32.4 \%)$ & $1364(60.4 \%)^{* * *}$ & $929(36.1 \%)$ & $2293(47.4 \%)$ \\
\hline \multicolumn{7}{|l|}{ Age (years) } \\
\hline $25-34$ & $684(28.8)$ & $809(26.9)$ & $1493(27.7)$ & $454(20.1)$ & $500(19.4)$ & $954(19.7)$ \\
\hline $35-44$ & $571(24.0)^{*}$ & $634(21.1)$ & $1205(22.4)$ & $483(21.4)^{*}$ & $481(18.7)$ & $964(20.0)$ \\
\hline $45-49$ & $418(17.6)^{*}$ & $469(15.6)$ & $887(16.5)$ & $420(18.6)$ & $429(16.7)$ & $849(17.6)$ \\
\hline $55-64$ & $313(13.2)$ & $448(14.9)$ & $761(14.1)$ & $395(17.5)$ & $409(15.9)$ & $804(16.6)$ \\
\hline$\geq 65$ & $393(16.5)^{* * *}$ & $644(21.4)$ & $1037(19.3)$ & $507(22.4)^{* * *}$ & $755(29.3)$ & $1262(26.1)$ \\
\hline missing data & - & - & - & - & - & - \\
\hline \multicolumn{7}{|l|}{ Age at smoking onset (for ever smokers) } \\
\hline$\leq 17$ & $560(58.0)^{* * *}$ & $332(43.0)$ & $892(51.3)$ & $726(58.6)^{* * *}$ & $379(47.5)$ & $1105(54.2)$ \\
\hline $18-20$ & $293(30.4)$ & $259(33.6)$ & $552(31.8)$ & $393(31.7)^{*}$ & $220(27.6)$ & $613(30.1)$ \\
\hline$\geq 21$ & $112(11.6)^{* * *}$ & $181(23.4)$ & $293(16.9)$ & $121(9.8)^{* * *}$ & $199(24.9)$ & $320(15.7)$ \\
\hline missing data & $4(0.4)$ & $3(0.4)$ & $7(0.4)$ & - & - & - \\
\hline \multicolumn{7}{|l|}{ Education } \\
\hline incomplete and complete primary & $786(33.6)$ & $1004(34.0)$ & $1790(33.8)$ & $1402(62.1)^{* * *}$ & $1437(55.8)$ & $2839(58.7)$ \\
\hline incomplete secondary & $424(18.1)^{* * *}$ & $425(14.4)$ & $849(16.0)$ & $415(18.4)$ & $468(18.2)$ & $883(18.3)$ \\
\hline secondary completed & $544(23.3)$ & $658(22.3)$ & $1202(22.7)$ & $249(11.0)^{* * *}$ & $450(17.5)$ & $699(14.5)$ \\
\hline incomplete and complete tertiary or university & $586(25.6)^{* *}$ & $868(29.4)$ & $1454(27.5)$ & $193(8.5)$ & $219(8.5)$ & $412(8.5)$ \\
\hline missing data & $39(1.6)$ & $49(1.6)$ & $88(1.6)$ & - & - & - \\
\hline \multicolumn{7}{|l|}{ Economical activity } \\
\hline employed & $1178(49.6)^{* * *}$ & $1022(34.0)$ & $2200(40.9)$ & $1277(56.5)^{* * *}$ & $987(38.3)$ & $2264(46.8)$ \\
\hline self-employed & $615(25.9)^{* * *}$ & $246(8.2)$ & $861(16.0)$ & $423(18.7)^{* * *}$ & $243(9.4)$ & $666(13.8)$ \\
\hline student & $43(1.8)^{*}$ & $77(2.6)$ & $120(2.2)$ & $5(0.2)$ & $13(0.5)$ & $18(0.4)$ \\
\hline homemaker & $2(0.1)^{* * *}$ & $895(29.8)$ & $897(16.7)$ & $5(0.2)^{* * *}$ & $390(15.2)$ & $395(8.2)$ \\
\hline retired & $418(17.6)^{* * *}$ & 702 (23.4) & $1120(20.8)$ & $453(20.1)^{* * *}$ & $742(28.8)$ & 1195 (24.7) \\
\hline unemployed & $118(5.0)^{* * *}$ & $61(2.0)$ & $179(3.3)$ & $96(4.2)^{* * *}$ & $199(7.7)$ & $295(6.1)$ \\
\hline missing data & $5(0.2)$ & $1(0.1)$ & $6(0.1)$ & - & - & - \\
\hline \multicolumn{7}{|l|}{ Asset Index } \\
\hline high (8-10pkt) & $1567(66.1)^{* *}$ & $1867(62.4)$ & $3434(64.0)$ & $1270(56.2)$ & $1489(57.8)$ & 2759 (57.1) \\
\hline middle (4-7 pkt) & $763(32.2)^{* *}$ & $1093(36.5)$ & $1856(34.6)$ & $886(39.2)$ & $1030(40.0)$ & 1916 (39.6) \\
\hline low (0-3 pkt) & $42(1.8)^{*}$ & $33(1.1)$ & $75(1.4)$ & $103(4.6)^{* * *}$ & $55(2.1)$ & $158(3.3)$ \\
\hline missing data & $7(0.3)$ & $11(0.4)$ & $18(0.3)$ & - & - & - \\
\hline \multicolumn{7}{|l|}{ Awareness of smoking health consequences } \\
\hline yes & $2317(98.7)$ & $2934(98.5)$ & $5251(98.6)$ & $2178(97.9)$ & $2500(98.2)$ & $4678(98.1)$ \\
\hline no & $31(1.3)$ & $46(1.5)$ & $77(1.5)$ & $46(2.1)$ & $45(1.8)$ & $91(1.9)$ \\
\hline missing data & $31(1.3)$ & $24(0.8)$ & $55(1.1)$ & $35(1.6)$ & $29(1.1)$ & $64(1.3)$ \\
\hline \multicolumn{7}{|l|}{ Awareness of smoking ETS consequences } \\
\hline yes & $2204(96.2)^{*}$ & $2841(97.3)$ & $5045(96.8)$ & $2218(98.5)$ & $2537(98.8)$ & 4755 (98.6) \\
\hline no & $88(3.8)^{*}$ & $80(2.7)$ & $168(3.2)$ & $34(1.5)$ & $31(1.2)$ & $65(1.4)$ \\
\hline missing data & $87(3.7)$ & $83(2.7)$ & $170(3.2)$ & $7(0.3)$ & $6(0.2)$ & $13(0.3)$ \\
\hline \multicolumn{7}{|l|}{ Cohabitation with a smoker } \\
\hline yes & $519(21.9)^{* * *}$ & $800(26.8)$ & $1319(24.6)$ & $716(31.7)$ & $791(30.7)$ & $1507(31.2)$ \\
\hline nho & $1849(78.1)^{* * *}$ & $2187(73.2)$ & $4036(75.4)$ & $1543(68.3)$ & $1783(69.3)$ & $3326(68.8)$ \\
\hline \multirow[t]{2}{*}{ missing data } & $11(0.5)$ & $17(01.6)$ & $28(0.5)$ & - & - & - \\
\hline & $N=2379$ & $N=3004$ & $N=5383$ & $N=2259$ & $N=2574$ & $N=4833$ \\
\hline
\end{tabular}


years, compared to $52.8 \pm 15.7$ years in Uruguay. Similarly, female ever smokers were $47.8 \pm 15.2$ years, on average, in Argentina, with $47.7 \pm 15.1$ years in Uruguay $(\mathrm{p}<0.05)$.

In the same vein, current male smokers in Argentina were $43.1 \pm 13.2$ years vs. $47.0 \pm 13.8$ years in Uruguay, while the female smokers were $44.6 \pm 13.7$ years and $44.9 \pm 13.6$ years in Argentina and Uruguay, respectively $(\mathrm{p}>0.05)$. At the mean, former smokers were a bit older in both countries; $54.3 \pm 15.8$ years and $58.6 \pm 15.4$ years for men and $51.8 \pm$ 16.1 years and $51.2 \pm 16.1$ years for women in Argentina and Uruguay, respectively ( $\mathrm{p}<0.04)$. Recent quitters were $39.7 \pm 125$ vs. $48.0 \pm 14.4$ for men and $39.2 \pm 13.5$ vs. $48.0 \pm 14.4$ years for women in both Argentina and Uruguay, in that order $(\mathrm{p}>0.05)$.

Following the same trend, women started smoking later than men in both countries (data not shown). Former and current male smokers started smoking by $17.3 \pm 5.1$ and $17.1 \pm 4.5$ years in Argentina vs. $16.7 \pm 4.6$ and $17.0 \pm 5.0$ years in Uruguay, respectively. Also, female former and current smokers in Argentina started at $19.6 \pm 6.5$ and $19.4 \pm 7.5$ years vs. $19.8 \pm 7.8$ and $19.2 \pm 6.7$ years in Uruguay, respectively (men vs. women $\mathrm{p}<0.001)$.

Alternatively, a higher quit rate was observed among women relative to men in Argentina; 39.6\% for women compared to $38 \%$ for men, and a lower quit rate in Uruguay; $50.1 \%$ for women compared to $52.7 \%$ for men $(\mathrm{p}>0.05)$.
Interestingly, women who successfully quit, did so at a slightly younger age than men. The mean age of quitting for male and female former smokers was $38.9 \pm 13.2$ and $37.7 \pm 13.9$ years, respectively, in Argentina, and $41.7 \pm 14.3$ and $38.3 \pm 14.3$ years, respectively in Uruguay $(\mathrm{p}>0.05)$.

Univariate regression. In both countries, men older than 45 years were more likely to be long-term quitters relative to those aged 35-44, but those over the age of 65 had the highest likelihood to maintain cessation; Argentina (OR=7.61; 95\% CI 4.76 - 12.16) and Uruguay (OR=4.70; 95\% CI 3.29 $6.73 ; \mathrm{p}<0.001)$. Similar results were obtained among women (Tab. 3). In Argentina, men with complete or incomplete secondary education had a lower likelihood to be long-term quitters $(\mathrm{OR}=0.62 ; 95 \%$ CI $0.42-0.92 ; \mathrm{p}<0.05)$ relative to those in the tertiary level (Tab. 2). Results for women in Argentina were not statistically significant. In Uruguay, education did not produce statistical significant results for either men or women. Retired men in Argentina had higher odds of quitting smoking for the long-term then employed men (OR=5.47; 95\% CI 3.77 - 7.94; p<0.001). Results were statistically insignificant among Uruguayan men. Similarly among women, retired respondents showed better prospects to be long-term quitters in Argentina $(\mathrm{OR}=3.58 ; 95 \% \mathrm{CI} 2.36$ - 5.44; $\mathrm{p}<0.001)$ and Uruguay $(\mathrm{OR}=4.70 ; 95 \%$ CI 3.29 - 6.73; $\mathrm{p}<0.001)$. Asset index was also a significant predictor of long-

Table 2. Odds Ratios (OR) and 95\% Confidence Intervals (Cl) for maintenance of smoking cessation for one year or over to selected characteristics in men- Global Adult Tobacco Survey Argentina 2012 (long-term quitter =377, current smoker =563) and Global Adult Tobacco Survey Uruguay 2009 (long-term quitter $=720$, current smoker $=600$ )

\begin{tabular}{|c|c|c|c|c|c|c|c|c|}
\hline \multirow{3}{*}{$\begin{array}{l}\text { Variable } \\
\text { Age (years) }\end{array}$} & \multicolumn{4}{|c|}{ Argentina } & \multicolumn{4}{|c|}{ Urugway } \\
\hline & \multicolumn{2}{|c|}{ Univariable logistic regression } & \multicolumn{2}{|c|}{ Multivariable logistic regression ${ }^{a}$} & \multicolumn{2}{|c|}{ Univariable logistic regression } & \multicolumn{2}{|c|}{ Multivariable logistic regression ${ }^{a}$} \\
\hline & & & & & & & & \\
\hline $25-34$ & 0.69 & $0.44-1.10$ & 0.76 & $0.48-1.21$ & $0.65^{*}$ & $0.45-0.95$ & $0.63^{*}$ & $0.43-0.93$ \\
\hline $35-44$ & 1.00 & reference & 1.00 & reference & 1.00 & reference & 1.00 & reference \\
\hline $45-54$ & $1.95^{* *}$ & $1.26-3.01$ & $2.03^{* *}$ & $1.30-3.16$ & 1.02 & $0.74-1.42$ & 1.00 & $0.70-1.44$ \\
\hline$\geq 65$ & $7.61^{* * *}$ & $4.76-12.16$ & $5.94^{* * *}$ & $3.00-11.77$ & $4.70^{* * *}$ & $3.29-6.73$ & $5.37^{* * *}$ & $3.69-7.82$ \\
\hline \multicolumn{9}{|l|}{ Education } \\
\hline $\begin{array}{l}\text { incomplete and } \\
\text { complete primary }\end{array}$ & 1.19 & $0.85-1.67$ & $0.65^{*}$ & $0.43-0.97$ & 1.01 & $0.66-1.54$ & & \\
\hline incomplete secondary & $0.65^{*}$ & $0.44-0.95$ & 0.74 & $0.48-1.14$ & 0.88 & $0.54-1.43$ & & \\
\hline secondary completed & $0.62^{*}$ & $0.42-0.92$ & $0.56^{* *}$ & $0.36-0.87$ & 1.11 & $0.65-1.90$ & & \\
\hline $\begin{array}{l}\text { incomplete and } \\
\text { complete tertiary } \\
\text { or university }\end{array}$ & 1.00 & reference & 1.00 & reference & 1.00 & reference & & \\
\hline \multicolumn{9}{|l|}{ Economic activity } \\
\hline employed & 1.00 & reference & 1.00 & reference & 1.00 & reference & & \\
\hline self-employed & 1.01 & $0.73-1.40$ & 0.86 & $0.60-1.22$ & 0.98 & $0.21-8.13$ & & \\
\hline homemaker & - & - & - & - & - & - & & \\
\hline retired & $5.47^{* * *}$ & $3.77-7.94$ & 1.41 & $0.79-2.52$ & 3.11 & $0.17-5.24$ & & \\
\hline unemployed & 0.85 & $0.45-1.61$ & 0.95 & $0.46-1.99$ & 0.46 & $0.33-2.18$ & & \\
\hline \multicolumn{9}{|l|}{ Asset Index } \\
\hline high & 1.00 & reference & & & 1.00 & reference & 1.00 & reference \\
\hline middle & 0.79 & $0.60-1.04$ & & & $0.70^{* *}$ & $0.56-0.88$ & $0.57^{* * *}$ & $0.45-0.73$ \\
\hline low & 0.47 & $0.15-1.45$ & & & $0.55^{* *}$ & $0.33-0.91$ & $0.33^{* * *}$ & $0.19-0.57$ \\
\hline
\end{tabular}

a Fully adjusted model including all statistically significant variables

${ }^{*} \mathrm{p} \leq 0.05$.

$* * p \leq 0.01$

$* * * 0 \leq 0.001$ 
Table 3. Odds Ratios (OR) and 95\% Confidence Intervals (CI) for maintenance of smoking cessation for one year or over to selected characteristics in women- Global Adult Tobacco Survey Argentina 2012 (long-term quitter =307, current smoker =430) and Global Adult Tobacco Survey Urugway 2009 (long-term quitter $=465$, current smoker $=423$ )

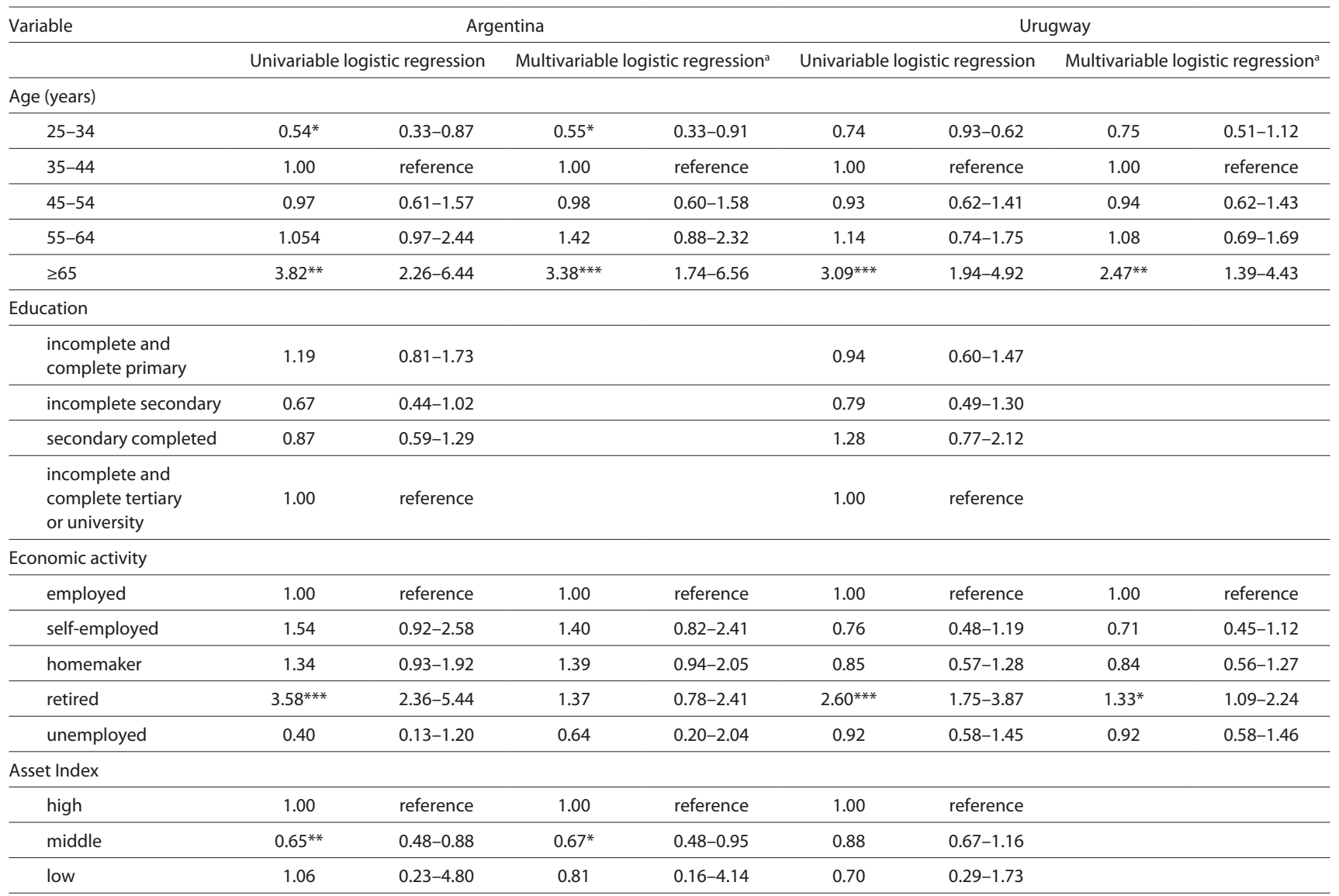

a Fully adjusted model including all statistically significant variables

${ }^{*} \mathrm{p} \leq 0.05$.

** $p \leq 0.01$.

$* * * 0.001$

term cessation among Argentinian women and Uruguayan men (Tab. 2, 3).

Multivariate regression. As in the univariate section, there was a significant association between age and long-term smoking cessation. Men older than 65 years had higher odds of quitting smoking long-term in Argentina (OR=5.94; 95\% CI $3.00-11.77 ; \mathrm{p}<0.001)$ and Uruguay $(\mathrm{OR}=5.37$; $95 \% \mathrm{CI}$ $3.69-7.82 ; \mathrm{p}<0.001)$, relative to those aged $35-44$. Similar results were observed among women in Argentina (OR=3.38; $95 \%$ CI $1.74-6.56$; $\mathrm{p}<0.001)$ and Uruguay $(\mathrm{OR}=2.47 ; 95 \% \mathrm{CI}$ $1.39-4.43 ; \mathrm{p}<0.001)$. The evidence showed no statistically significant association between economic activity and being a long-term quitter among men in both countries, and women in Argentina. On the other hand, retired women in Uruguay $(\mathrm{OR}=1.33$; 95\% CI $1.09-2.24 ; \mathrm{p}<0.05)$ were more likely to be long-term quitters relative to those currently employed. Similar to the univariate section, men and women with a high asset index had an increased likelihood of maintaining their status as long-term quitters.

\section{DISCUSSION}

Understanding potential social gradients in the population and its relation to quitting have significant implications for the development of a future population strategy for smoking cessation. The majority of studies on smoking cessation are derived from a Western context; it was therefore uncertain whether these findings would apply to two neighbouring Latin American countries - Argentina and Uruguay.

Firstly, in Argentina, a lower lifetime quit rate was noticed compared to Uruguay (39.2\% vs. $51.7 \%$ ). This data coincides with trends observed in recent years showing greater progress in Uruguay than in Argentina, as it relates to many areas of tobacco control. Recent trends also showed intensified tobacco industry endeavours to postpone or undermine tobacco control legislation and policy in Argentina [20,21, 22]. However, in both countries, quit rates were higher compared to middle-income European countries like Romania and Poland where one third of the people who have ever smoked gave up smoking [14, 23]. Conversely, quit rates in Argentina and Uruguay are lower when compared to more developed countries, for example, Canada, where the quit rate reaches $60 \%$ [24]. This suggests that huge gaps still exist among countries in terms of the implementation, enforcement, and comprehensiveness of tobacco control efforts to curb the tobacco epidemic, including cessation measures.

While the majority of studies on socio-economic inequalities in smoking have focused on education and used smoking prevalence as the outcome interest, the presented analysis focused on more than one particular 
dimension and being a successful quitter [16]. Although there is some variability in the findings, socio-economic conditions have been identified as a predictor of quit attempts and quitting success in a number of studies [25, 26,27]. De Maio et al. found a reverse gradient, based on the GATS data, although lacking statistical significance, in smoking cessation attempts which were reported more frequently in the recent year by Argentineans and Uruguayans with lower levels of education [3]. However, when analyzing education and cessation success, in the current study it was found that men in Argentina with lower education attainment also had reduced odds to achieve tobacco abstinence for a year or more. Lower education results from the regression analysis for women in Argentina and respondents from Uruguay did not produce any statistically significant results. In general, this may suggest that male Argentineans with lower educational background are more likely to attempt to quit, but they are less likely to sustain abstinence compared to those with higher education. This is in line with the findings of Kotz et al. who indicated that smokers in more deprived socioeconomic groups are just as likely as those in higher groups to attempt stopping smoking. However, there is a strong gradient of success across socio-economic groups, with those in the lowest group being half as likely to succeed compared with the highest [28]. On the other hand, some studies have not found a relationship between socio-economic factors and quitting, particularly in multivariate analyses which also include other important characteristics [14]. The figures of the International Tobacco Control Four Country Survey showed that education was not generally associated with cessation success, although a few particular levels in certain countries were significantly associated with quitting success [29]. Furthermore, Siahpush et al. in a study of a national sample of Australians confirmed that while education had the strongest relationship with smoking cessation, of all the factors controlled, the relationship between higher education and increased odds of cessation no longer existed when other environmental and individual variables were included in the model [30].

Moreover, in the presented study it was noticed that retired women from Uruguay had higher odds of successfully quitting. This success can be linked with the fact that this group covers older people who are more likely to quit mostly due to health reasons, as previously discussed. In Argentina and Uruguay, unemployed respondents had decreased odds for successfully quitting, but the results were not statistically significant compared to each other. Figures from other GATS-based studies brought mixed results in this area. Being economically active was associated with long-term quitting among men in Romania [14]. In GATS Poland, employed males also had more than twice the probability of giving up smoking compared with the unemployed [23]. The association with employment status among women has not been observed in either country. However, GATS revealed that long-term smoking cessation was harder for men from disadvantaged groups with low asset indices from Argentina and Uruguay. Lower socio-economic groups are generally less likely to be successful quitters, although there is some variation $[6,27,31,32,33]$. These findings are mostly based on education and/or income data and cannot be compared with GATS results directly considering asset index. Further studies of the expected social gradients in quitting and asset index are needed.
Study strengths and limitations. The data derived from GATS is the most recent, nationally representative data based on a high number of respondents. It considers various potential cessation predictors which may also contain some limitations. For the purpose of this study, subjects were selected who were aged 25 years or older at the time of the survey. The analysis was restricted to individuals aged 25 and above because they might still be engaged in the process of smoking uptake [34]. Moreover, subjects under 25 might not have completed the maximum level of education [35]. In addition, continuous abstinence for twelve months or longer was assessed by self-reporting and not validated. Selfreport methods are the most convenient and cheapest way to collect data on smoking tobacco from a large number of respondents in a short time. However, the possible limitation in obtaining answers about smoking may be recall bias, which might lead to underestimation of tobacco consumption. Nonetheless, self-report techniques are stated to be a valid tool for population studies, as addressed in previous papers [36].

Although the GATS questionnaire included questions on duration of tobacco smoking and age of smoking onset, the nicotine dependence or heaviness of smoking that are considered important determinants of, were not obtained for former smokers who maintained tobacco abstinence over one year in this data. There was no information on successful quitting for sustained quitters, such as number of quit attempts, duration per quit attempt, or details on assisted or unassisted quitting. Due to the unavailability of data, it was also not possible to compare some other information from Argentina and Uruguay with other countries; quitting motivations, impact of previous tobacco control measures, including tobacco tax increase. Another limitation is the inability to draw conclusions in causality or directionality of some results based on the cross-sectional study design. Nevertheless, in contrast to studies evaluating the efficacy of smoking cessation treatment programmes, or cessation in high risk groups of heart disease patients, the presented study population should be more representative of the great majority of quitters who quit on their own [18]

\section{CONCLUSIONS}

The GATS study revealed that a social gradient in tobacco quitting exists in Argentina and Uruguay. It also identified characteristics associated with long-term sustained tobacco abstinence in both countries. This study provided an insight in specific categories beyond age and gender that were not broadly studied previously, such as asset index. The current study also highlighted the need to encourage tobacco measures that focus on the population that have a harder time quitting smoking. These include younger people, and special attention should be paid to young groups aged 25-34, particularly men in Uruguay and women in Argentina, low educated people and those with lower economic position characterized by asset index. A number of evidence-based individual or community-based policies delivered according to the social context that successfully work in other countries and targeted socially disadvantaged groups, could be adopted in Argentina and Uruguay [37, 38, 39]. This may facilitate the reduction of inequalities in tobacco-related harm within populations. This is because if tobacco consumption is to be 
addressed across all social groups, without the distribution of impacts, the improvement will not be experienced equally everywhere, or by everyone [7]. Finally, further systematic research is needed to understand factors that are driving differences in quitting tobacco smoking between diverse social groups in Latin America countries, to ensure tobacco control policies work effectively for all population groups.

\section{Acknowledgements}

The Bloomberg Philanthropies provided financial support to implement GATS Argentina as part of the Bloomberg Initiative to reduce tobacco consumption. The authors thank the Survey Team involved in GATS in Argentina, including Dr. Daniel Ferrante, Dr. Jonatan Konfino, Dr. Bruno Linetzky, Lic. Lucila Goldberg, Lic. Dolores Ondarsuhu. Additional thanks are extended to the Survey Team involved in the GATS in Uruguay; GATS Partners: Bureau of Health Promotion and Control of Non-communicable Diseases, the Ministry of Health of the Nation and Coordination of Special Surveys of the Bureau of Household Income and Expenditures Studies of the National Institute of Statistics and Censuses, and representatives of the Pan American Health Organization/World Health Organization (PAHO/ WHO), the US Centers for Disease Control and Prevention (CDC), CDC Foundation, Johns Hopkins Bloomberg, School of Public Health and the Research Triangle Institute (RTI) for their contribution. Thankful are also due to the CDC, Atlanta, USA, for making available the GATS data.

\section{REFERENCES}

1. Pan American Health Organization. Tobacco Control Report for the Region of the Americas. Washington, DC, USA, 2013.

2. World Health Organization. WHO global report: mortality attributable to tobacco. World Health Organization, Geneva, Switzerland, 2012.

3. De Maio FG, Konfino J, Ondarsuhu D, Goldberg L, Linetzky B, Ferrante D. Sex-stratified and age-adjusted social gradients in tobacco in Argentina and Uruguay: evidence from the Global Adult Tobacco Survey (GATS). Tobacco Control, 2014; pp.1-6. doi:10.1136/ tobaccocontrol-2013-051525 2014 July 1.

4. Centers for Disease Control and Prevention (CDC). Best practices for comprehensive tobacco control programs. Atlanta: U.S. Department of Health and Human Services, Centers for Disease Control and Prevention, National Center for Chronic Disease Prevention and Health Promotion, Office on Smoking and Health, 2007.

5. World Health Organization. Systematic review of the link between tobacco and poverty. World Health Organization, Geneva, Switzerland, 2011.

6. Fleischer NL, Diez Roux AV, Alazraqui M, Spinelli, Lantz PM. Socioeconomic patterning in tobacco use in Argentina, 2005. Nicotine Tobacco Res. 2011; 13: 894-902.

7. World Health Organization. Tobacco and i equalities. Guidance for addressing inequalities in tobacco-related harm". World Health Organization, Copenhagen, Denmark, 2014.

8. Global Adult Tobacco Survey (GATS). Argentina Country Report. Ministry of Health Argentina: 2012. http://www.who.int/tobacco/ surveillance/survey/gats/argentina/en/index.html (Accessed July 2014)

9. Pan American Health Organization. Global Adult Tobacco Survey. Uruguay GATS Report 2009, Uruguay. WHO/PAHO, 2011.

10. Centers for Disease Control and Prevention (CDC). Global Tobacco Surveillance System. Global Adult Tobacco Survey. Atlanta: Centers for Disease Control and Prevention, 1999.

11. Lee C, Kahende J. Factors associated with successful smoking cessation in the United States, 2000. Am J Public Health. 2007; 97: 1503-1509.

12. Bjornson W, Rand C, Connett JE, Lindgren P, Nides M, Pope F, Buist AS, Hoppe-Ryan C, O'Hara P. Gender differences in smoking cessation after 3 years in the Lung Health Study. Am J Public Health. 1995; 85: 223-230.
13. Srivastava S, Malhotra S, Harries AD, Lal P, Arora M. Correlates of tobacco quit attempts and cessation in the adult population of India: secondary analysis of the Global Adult Tobacco Survey, 2009-10. BMC Public Health. 2013; 13: 263. Published online 2013 March 22. doi: 10.1186/1471-2458-13-263 D.

14. Kaleta D, Usidame B, Dziankowska-Zaborszczyk E, MakowiecDąbrowska T. Correlates of Cessation Success among Romanian Adults. BioMed Research International. 2014: 675496. Published online 2014 June 4. doi: 10.1155/2014/675496.

15. West R, Mcewen A, Bolling K, Owen L. Smoking cessation and smoking patterns in the general population: a 1-year follow-up. Addiction. 2001; 96: 891-902.

16. Marti J. Successful smoking cessation and duration of abstinence-an analysis of socioeconomic determinants. Intern J Environ Res Public Health 2010; 7: 2789-2799.

17. Osler M, Prescott E. Psychosocial, behavioural, and health determinants of successful smoking cessation: a longitudinal study of Danish adults. Tobacco Control. 1998; 7(3): 262-67; doi: 10.1136/tc.7.3.262.

18. Kabat GC, Wynder EL. Determinants of quitting smoking. Am J Public Health. 1987; 77(10): 1301-1305.

19. Kaleta D, Usidame B, Dziankowska-Zaborszczyk E, MakowiecDąbrowska T, Leinsalu M. Prevalence and factors associated with hardcore smoking in Poland: findings from the Global Adult Tobacco Survey (2009-2010). BMC Public Health. 2014; 14: 583; doi: 10.1186/1471-2458-14-583 2014 Jun 11.

20. Alderete M, Gutkowski PM. Health is Not Negotiable: Civil Society against the Tobacco Industry's Strategies in Latin America. Case Studies 2014. Gutkowski; edited by Patricia Gutkowski. Second Edition. Buenos Aires: Inter-American Heart Foundation-Argentina, 2014. http://ficargentina.org/images/stories/Documentos/la_salud_no_se_ negocia 2014 in_final.pdf

21. Azevedo e Silva G, Valente JG. Tobacco control: Learning from Uruguay. Lancet 2012; 380: 1538-40.

22. Sebrié EM, Barnoya J, Perez-Stable EJ, Glantz SA. Tobacco industry successfully prevented tobacco control legislation in Argentina. Tobacco Control. 2005; 14: e2.

23. Kaleta D, Korytkowski P, Makowiec-Dabrowska T, Usidame B, Bak-Romaniszyn L, Fronczak A. Predictors of long-term smoking cessation: results from the global adult tobacco survey in Poland (2009-2010). BMC Public Health. 2012; 12: 1020.

24. Health Canada. Available from: http://www.hc-sc.gc.ca/hecs-sesc/ tobacco/research/ctums/2002/2002-supptables.eng.pdf. Accessed February 2014

25. Edwards R. The problem of tobacco smoking. BMJ. 2004; 328: 217-219. doi:10.1136/bmj.328.7433.217.

26. Vangeli E, Stapleton J, Smit ES, Borland R, West R. Predictors of attempts to stop smoking and their success in adult general population samples: a systematic review. Addiction. 2011; 106(12): 2110-2121.

27. Reid J, Hammond D, Boudreau C, Fong GT, Siahpush M. Socioeconomic disparities in quit intentions, quit attempts, and smoking abstinence among smokers in four western countries: Findings from the International Tobacco Control Four Country Survey. Nicotine Tobacco Res. 2010; 12, Suppl 1: S20-S33, 2010. doi: 10.1093/ntr/ntq051

28. Kotz D, West R. Explaining the social gradient in smoking cessation: it's not in the trying, but in the succeeding. Tobacco Control. 2009; 18(1): 43-46.

29. Hyland A, Borland R, Li Q, Yong HH, McNeill A, Fong GT, Connor RJO, Cummings KM. Individual-level predictors of cessation behaviours among participants in the International Tobacco Control (ITC) Four Country Survey. Tobacco Control. 2006; 15, suppl III: iii83-iii94.

30. Siahpush M, Borland R, Scollo M. Factors associated with smoking cessation in a national sample of Australians. Nicotine Tobacco Res.2003; 5: 597-602.

31. Marques-Vidal P, Melich-Cerveira J, Paccaud F, Waeber G, Vollenweider P, Cornuz J. Prevalence and factors associated with difficulty and intention to quit smoking in Switzerland. BMC Public Health. 2011; 13(11): 227.

32. Augustson EM, Wanke KL, S Rogers S, Bergen AW, Chatterjee N, Synder K, Albanes D, Taylor P, Caporaso NE. Predictors of sustained smoking cessation: a prospective analysis of chronic smokers from the alpha-tocopherol Beta-carotene cancer prevention study. Am J Public Health. 2008; 98: 549-555.

33. Donzé J, Ruffieux C, Cornuz J. Determinants of smoking and cessation in older women. Age and Ageing 2007; 36(1): 53-57. doi: 10.1093/ ageing/afl120 
34. Emery S, Gilpin EA, Ake C, Farkas AJ, Pierce JB. “Characterizing and identifying 'hard-core' smokers: implications for further reducing smoking prevalence”. Am J Public Health. 2000; 90: 387e94

35. Fernández E, Garcia M, Schiaffino A, Borràs JM, Nebot M, Segura A. Smoking initiation and cessation by gender and educational level in Catalonia, Spain. Prev Med. 2001; 32: 218-223.

36. Patrick DL, Cheadle A, DThompson DC, Diehr P, Koepsell T,. Kinne $\mathrm{S}$. The validity of self-reported smoking: A review and meta-analysis. Am J Public Health. 1994; 84(7): 1086-1093.

37. Wilson LM, Avila TE, Chander G, Hutton HE, Odelola OA, Elf JL, Heckman-Stoddard BM, Bass EB, Little, Haberl, Apelberg BJ. Impact of tobacco control interventions on smoking initiation, cessation, and prevalence: a systematic review. J Environ Public Health. 2012: 961724. doi: 10.1155/2012/961724. Epub 2012 Jun 7.

38. Murray RL, Bauld L, Hackshaw LE, McNeill A. Improving access to smoking cessation services for disadvantaged groups: a systematic review. J Public Health. 2009; 31(2): 258-77. doi: 10.1093/pubmed/ fdp008. Epub 2009 Feb 10.

39. Neumann T, Rasmussen M, Ghith N, Heitmann BL, Tønnesen H. The Gold Standard Programme: smoking cessation interventions for disadvantaged smokers are effective in a real-life setting. Tobacco Control, 2012. doi:10.1136/tobaccocontrol-2011-050194 